\title{
LARGE FRACTURE EXPERIMENTATION
}

Carl H. Sondergeld and Hartmut A, Spetzler

University of Colorado

CIRES

Boulder, Colorado 80309

USGS CONTRACT NO. 14-08-0001-19166

Supported by the EARTHQUAKE HAZARDS REDUCTION PROGRAM

OPEN-FILE NO. $81-941$

U.S. Geological Survey

OPEN FILE REPORT

This report was prepared under contract to the U.S. Geological Survey and has not been reviewed for conformity with USGS editorial standards and stratigraphic nomenclature. Opinions and conclusions expressed herein do not necessarily represent those of the USGS. Any use of trade names is for descriptive purposes only and does not imply endorsement by the USGS. 
Report Summary

Large Scale Fracture Experiment

C.H. Sondergeld and H.A. Spetzler

Cooperative Institute for Research in Environmental Sciences, University of Colorado/NOAA

We spent the month of October (1980) conducting a uniaxial compression test on a block of granite $(70 \mathrm{~cm} \times 70 \mathrm{~cm} \times 70 \mathrm{~cm})$ utilizing the large loading frame (445 MN) in Moscow. After enormous preparation we made available a totally portable acoustic emission monitoring system which provided capabilities for complete studies of microseismicity during rock deformation. The system was successfully mated to the experiment. Initial results indicate the following: (one) considerable energy is released in shear waves from the $\mathrm{AE}$ sources; two, an optimum volume which is smaller than the volume tested is preferrable for detailed $\mathrm{AE}$ studies; and three, parallel measurements are feasible on a time-sharing basis with large volume specimens. 


\section{A. Subject}

The major objective of this contract was to carry out a large scale uniaxial compression test using the Russian testing frame (445 MN). An acoustic emission monitoring system discussed in the technical report for contract 14-080001-18307 was used to perform microseismic studies during deformation (see also Sondergeld, 1980; Sondergeld and Estey, 1981).

B. Discussion

A rather successful experiment was carried out in Moscow. We recorded acoustic emission signals which will be used for hypocenter, velocity, attenuation and focal mechanism studies. Our Russian colleagues recorded force, strain, acoustic velocity, D.C. resistivity, electrical potential and electromagnetic emissions.

We affixed 24 piezoelectric transducers to the four exposed sides of the cubic specimen $(70 \mathrm{~cm} \times 70 \mathrm{~cm} \times 70 \mathrm{~cm})$. Four transducers were selected one from each face, and summed to act as a trigger for the system. Two transducers from each face were actually used to record the $\mathrm{AE}$ signals. It was clear from examining the low frequency arrivals ( $f<50 \mathrm{khz}$ ) that poiston sticking was taking place. Higher frequency waveforms were clearly coming from within the sample volume. The initial $\mathrm{AE}$ response of the rock was extremely quiet attesting to the uniformity of loading. When the AE activity started a cursory examination of both amplitude signal and spectral character of the recorded signals permitted us to quickly identify the octant of the cube in which deformation was taking place. Two of the most important observations were: one, the severe attenuation of acoustic emission signals over distances of about $70 \mathrm{~cm}$ and two, the dominance of S-waves from AE sources. When both the P-wave and S-wave were observed for the same signal, the $S$ wave was 5 to 10 times larger in amplitude than the P-wave. How are S-waves generated from simple tensile fractures 
which are presumed to exist during uniaxial compression?

The attenuation problem proved to be most limiting since it often precluded the recording of eight waveforms. Without 8 well recorded signals there is very little chance of determining the radiation pattern for the $A E$ event. An important lesson learned is that there exists an optimum volume for detailed AE studies which is considerably smaller than the $343,000 \mathrm{~cm}^{3}$ volume used in this experiment. This volume may vary with the rock type tested.

The uniaxial failure strength for a $5 \mathrm{~cm}$ diameter sample of the rock tested was $120 \mathrm{MPa}$. The failure strength obtained for the large cube was $140 \mathrm{MPa}$. Thus there still remains to be determined if a scale effect on rock strength exists. The cube tested had large albite and biotite veins. Suprisingly neither was the site of the recorded $\mathrm{AE}$ activity. Failure as referred to above was not catastrophic. A single stably propagating crack developed as the load dropped. $\mathrm{AE}$ activity increased dramatically and could be associated with the vicinity of the crack. Acoustic emissions recorded near the crack possessed amplitudes in excess of $-+10 v($ gain $=300)$ and exhibited higher frequencies than signals recorded farther away. Previously, typical signal levels rarely exceeded $\pm 400 \mathrm{mv}$.

Initial analysis of the velocity measurements indicates that all velocities increased. These measurements were made over paths perpendicular to the applied stress. Lower values of velocity were recorded near the edges of the specimen.

Electromagnetic emission studies proved fruitless as no effort was taken to shield out environmental noise, such as that generated by relays, motors, etc.

Electrical potential measurements made with calumel electrodes potted in a $\mathrm{KCl}$ solution indicated that measureable changes were taking place during the loading but this spatial position did not correspond to the site of the AE activity. 
C. Conclusions

More time is needed to complete analysis of the data. However, preliminary conclusions which may be drawn are:

(1) One does not need the excessive sample volume permitted by the large Russian loading frame for detailed acoustic emission studies. A loading system of one tenth its capacity is more than ample. (Estey et. al., 1980)

(2) Parallel measurements are possible on such large sample dimensions. These measurements are best carried out on a time-sharing basis.

(3) The energy released in shear waves dominates over that in P-waves.

D. Bibliography

Estey, L.H., C.H. Sondergeld, P. Halleck, J. Dey, and J. Blacic, Acoustic emissions associated with large volume and large grain size samples during uniaxial deformation, EOS 61, 1115, 1980.

Sondergeld, C.H. An effective noise discriminator for use in Acoustic emission studies, Rev. Sci. Instrum. 5l, 1342-1344, 1980.

Sondergeld, C.H. and L.H. Estey, Acoustic emission study of microfracturing during the uniaxial cycling of Westerly granite, J. Geophys. Res. in press, 1981. 
F. Implication for further research

The unique facility available to us through our Russian colleagues provided us with an opportunity to assess the worth of large volume specimens in acoustic emission work. We have learned a very worthwhile fact, namely, that more meaningful and cost effective acoustic emission studies could be carried out on much smaller specimens here in the United States. 
DESIRABLE SAMPLE DIMENSIONS FOR DETAM.ED ACOUSTIC EMISSION STUDIES

Carl H. Sondergeld* CIRES

University of Colorado

Boulder, CO 80309

*Now at:

Amoco Production Co.

Research Center

P.o. Box 591

Tulsa, Oklahoma 94102 


\begin{abstract}
Understanding why and how rocks fail under various conditions is absolutely crucial to understanding earthquakes, roof collapse in mines, hydraulic and gas fracturing processes, etc. Large sample dimensions enhance the resolution of detailed acoustic emission studies. Microseismological studies are made possible with increased sample dimensions. Furthermore, the physical dimensions permit numerous simultaneous studies which together provide rigid constraints on the physics of rock failure.
\end{abstract}

\title{
INTRODUCTION
}

This communication discusses some aspects of acoustic emission (AE) studies and the desire to extend these observations to larger sample dimensions. One of the most compelling reasons for studying acoustic emissions is that they eminate directly from the physical processes which we are trying to understand. Whether one is concerned with earthquake mechanisms, failure of geologic structures, or processes which stimulate reservoir production the study of the acoustic emission sources can yield vital information for the understanding of these processes. For example, the local downhole expression of a hydraulic fracture might not be simply related to the principal stress directions. Look for example at the early work of Brace and Bombolakis (1963) in which the eventual direction of crack propagation is markedly different than the initial direction. I might add that these tests were conducted on very simple materials in a very simple stress field. Using AE techniques one could map the progress of a hydraulic fracture and eliminate the ambiguity in interpretation. The need for large volume experimentation comes from the desire to extract more data from the $\mathrm{AE}$ records related to cracks, crack interactions, internal stresses, etc. $\mathrm{A}$ brief overview of the experiences in attempting to monitor AE events in large loading frames and some preliminary findings will also be discussed. 
Aside from the obvious shortcomings of small scale laboratory specimens a new problem arises when attempting to study the details of $\mathrm{AE}$ phenomenon. The limited physical dimensions force the sensors to be located in the "nearfield" of an AE source thus classical source theory cannot be used to deconvolve the source function. One also loses the usefulness of amplitude information in constraining the nodal planes of AE focal mechanisms. Further, identification of phases becomes difficult due to the arrival of reflections and sample resonances. The significance of AE hypocenter spatial patterns and their migration becomes masked by the limited spatial resolution. Ideally the larger specimen volumes would mitigate these limitation if it were not for scattercing and attenuation of the acoustic signals in the frequency bandwidth of interest ( $50 \mathrm{kHz}$ to $5 \mathrm{MHz}$ ). It has been established empirically that there exist an optimum volume for the type of $\mathrm{AE}$ studies, microseismic, to be discussed. In uniaxial compression, sample dimensions on the order of $30 \mathrm{~cm}$ in diameter by $75 \mathrm{~cm}$ long are most desirable. These dimensions will vary slightly with the acoustic properties of the rock sample and grain size. These dimensions would permit one to (1) locate $\mathrm{AE}$ events, and study their spatial patterns; (2) determine focal mechanisms and study their changes with deformation; (3) analyze spectral changes for source parameters i.e., stress drop, source dimension, rupture velocities, etc.; (4) invert travel time data for both active and passive systems for detailed velocity structure.

A most important aspect of any large scale experimentation is the opportunity to simultaneously or on a time-sharing basis carry out parallel measurements of other physical properties i.e., resistivity, electrical potential, strain, velocity, temperature, etc. Thus a more complete data set can be collected from a sample with one stress history. This point highlights one of the most severe criticisms of field precursors namely the lack of a total set of observa- 
tions for a single major earthquake. With a detailed set of observations one is in a better position to formulate a physical model for the processes leading to failure.

\section{ACOUSTIC EMISSION DURING LARGE VOLUME TESTING}

As a preface to this section I would like to point out that small scale loading frames and tests do have definite attributes for $\mathrm{AE}$ monitoring. The frames can be completely enclosed in a Faraday shield and noise levels can be controlled to a large extent. The physical size of the larger loading frames does not permit one to lavishly enclose the press in copper screening. Also due to the longer lengths of cable and the low voltage levels of the $\mathrm{AE}$ signals placement of the amplifiers and incorporation of line drivers is critical. As part of our learning experience in adopting the $\mathrm{AE}$ monitoring system described by Sondergeld and Estey (1981) and Sondergeld (1980) to the large scale experiments, four tests were carried out, two at Los Alamos Scientific Laboratories (Estey et al., 1980) and two at the Institute of High Pressure Physics in the Soviet Union. These experiments will be described in chronological order.

Preliminary tests were carried out on a 50,000 Ton ( $445 \mathrm{MN}$ ) hydraulically actuated loading frame at the Institute of High Pressure Physics with Soviet colleagues from the Institute of Physics of the Earth. During these tests a $35 \mathrm{~cm} \mathrm{x}$ $35 \mathrm{~cm} \times 70 \mathrm{~cm}$ block of granite (g.s. $\approx 6 \mathrm{~mm}$ ) was loaded stepwise in uniaxial compression. Acoustic emissions were detected and could be distinguished from environmental noise. Uniform loading of the rock posed a serious problem at this stage. Failure strength as determined from the loading in the support frame was approximately $80 \mathrm{MPa}$. The specimen did not fail catastrophically. A stably propagating crack was observed and its velocity could be controlled by controlling the load.

The first successful adaptation of our AE system took place at Los Alamos 
during the uniaxial testing of a specimen of Texas pink granite $(35 \mathrm{~cm}$ in diameter by $36 \mathrm{~cm}$ long). In this test a 5,000 Ton (44 MN) loading frame was used. Force was monitored via the oil pressure driving the ram and with strain gages attached to steel end caps. Ten piezoelectric crystals ( $1 \mathrm{MHz}, 9.5 \mathrm{~mm}$ diameter PZT-5A) were bonded to the surface, only eight were used to detect AE activity. The other two were used as active sources for velocity measurements. Similar tests were run on a $2.54 \mathrm{~cm}$ and a $5.4 \mathrm{~cm}$ diameter cores of Texas pink granite. The smaller samples had strengths of $108 \mathrm{MPa}$ and $127 \mathrm{MPa}$, respectively. The larger core gave a strength of about $110 \mathrm{MPa}$. The length to diameter ratio of the large sample would favor the apparent high strength. Again sample failure was not catastrophic in the larger sample, stable cracking dominated the process. The associated $\mathrm{AE}$ activity was sampled. Eight strong and clear arrivals could be recorded for most events. The larger sample permitted us to clearly identify both $\mathrm{P}$ and S-wave arrivals (see Figure 1). The S-amplitudes dominated often being 5 to 10 times the P-wave amplitudes. The magnitude of the events increased as well as their frequency of occurrence as loading progressed. The $\mathrm{AE}$ rate became so great that it became impossible to capture single events in the $200 \mu$ sec window. Thus the usefulness of events captured prior to failure is in doubt for this particular acoustically active rock at the strain rate employed.

A third large scale experiment was carried out this fall in Russia. The AE system was used during the uniaxial compression of a $70 \mathrm{~cm}$ by $70 \mathrm{~cm}$ by $70 \mathrm{~cm}$ cube of granite (g.s. $\approx 4 \mathrm{~mm}$ ). This rock possessed a number of inhomogeneities including veins of biotite and albite. Measurement of strain with $150(5 \mathrm{~cm})$ strain gages, DC electrical resistivity, electrical potential and acoustic velocities were all done on a time-sharing basis. In general, velocities measured over numerous paths in a direction perpendicular to loading showed an increase. Initial $\mathrm{AE}$ activity was extremely low due to the improvement in load uniformity. 
Most events dominated by low frequencies could be linked to mechanical noises associated with the loading frame. Attenuation and scattering in samples of this dimension precluded the record quality obtained at Los Alamos or in small samples. Often only nearby stations would record an event with obviously filtered responses at not too distant stations. Perhaps a more sophisticated arrangement whereby arrays of nearby sensors could be switched into the transient recorders would prove more fruitful. Nevertheless, one could again clearly distinguish arrivals as being $P$ and $S$ waves with the $S$ waves having by far the dominant amplitudes. By simply monitoring the amplitude and frequency content of $\mathrm{AE}$ waveforms at individual sensors, the site of failure could be determined. Clearly a simple envelope detector would suffice for crude locating schemes in large specimens. Using an amplification of $\sim 50 \mathrm{db}$ typical signal levels were \pm $200 \mathrm{mv}$, however, associated with the development of a single visible crack were signals of $\pm 10 \mathrm{v}$ in amplitude for transducers within $\sim 5 \mathrm{~cm}$ of the crack. Again the failure was not catastrophic, upon unloading the crack was contained within the rock. The load sustained prior to crack formation was $140 \mathrm{MPa}$ and the $5 \mathrm{~cm}$ diameter core failure was determined to be $120 \mathrm{MPa}$.

\section{SUMMARY}

It is clear from these preliminary tests that an optimum sample volume exists for studies of $\mathrm{AE}$ event hypocenters and the details of $\mathrm{AE}$ source mechanisms. With extremely large samples signals suffer attenuation of higher frequencies thus reducing the number and quality of signals recorded by a fixed array of sensors. The optimum sample volume depends upon the rock type, the frequencies of interest and type of $\mathrm{AE}$ information desired. Even simple event counting must include consideration of the attenuation problem. One would optimize the volume by considering the wavelength of the radiated signals and fabricating a specimen so that for most $\mathrm{AE}$ activity all the sensors are in the "far 
field". With the dominant frequencies of $100 \mathrm{KHz}$ to $1 \mathrm{MHz}$ this requires an approximate average source-receiver range of $40 \mathrm{~cm}$ to $4 \mathrm{~cm}$ for these two frequencies. Unfortunately, the $1 \mathrm{MHz}$ signals do not dominate even in the small specimens tested to date. The smaller specimens do not permit the unambiguous identification of S-waves thus samples with minimum dimensions of $10 \mathrm{~cm}$ to $15 \mathrm{~cm}$ are desirable in this regard.

Attempting to count $\mathrm{AE}$ events and their rate of occurrence in large samples requires consideration. Initial attempts at such measurements indicate that the data reflect only very local changes. Counting over different volumes of the total volume provide crude estimate of damage location and can often vary in absolute counts by factors of 10,000 or more.

In addition to the acquisition of $\mathrm{AE}$ data, a number of pertinent observations were given which raise troubling questions. Does there exist a scale effect on rock strength? The data presented by Brace (this issue, 1981) suggests that there might exist some scale effect. However, the strength and dimensioans given in this paper raise doubt about a scale effect in brittle rock. This question obviously needs much more attention. After noting that the failure of large specimens in very soft machines is progressive and not catastrophic one seriously questions the degree to which the response of small samples in very stiff machines can be considered intrinsic to the rock.

\section{ACKNOWLEDGMENTS}

This report summarizes some initial results stemming from cooperative research efforts with Drs. P. Halleck, T. Dey, J. Blacic, R. Riecker, J. Byerlee, H. Spetzler, G. Sobolev and Mr. L. Estey. I am grateful to the institutions which made their facilities available to me: Los Alamos National Laboratory and the Institute of the Physics of the Earth (USSR). The support of the USGS under contract 14-08-001-19166, the National Science Foundation under grants EAR- 
7823851, EAR 8019493 and Los Alamos National Laboratories are gratefully acknowledged.

\section{FIGURE CAPTIONS}

Figure 1. A typical recording of one channel acoustic emission event. The horizontal and vertical scales are $1 \mathrm{~cm}=24.5 \mu \mathrm{sec}$ and $1 \mathrm{~cm}=63.5 \mathrm{mv}$, respectively. The $\mathrm{P}$-wave arrival can be clearly identified and is labeled 1. The S-wave arrival is picked at 2 . Note the relative proportioning of energies between the $\mathrm{P}$ and $\mathrm{S}$ waves.

\section{REFERENCES CITED}

Brace, W. The effect of size on mechanical properties of rock, Geophys. Res. Lett., this volume, 1981.

Brace, W.F. and E.G. Bombolakis. A note on brittle crack growth in compression, J. Geophys. Res., 68, 3709-3713, 1963.

Estey, L.H., C.H. Sondergeld, P. Halleck, T. Dey and J. Blacic. Acoustic emissions associated with large volume and large grain size samples during uniaxial deformation, EOS, 61, 1115, 1980.

Sondergeld, C.H. An effective noise discriminator for use in acoustic emission studies, Rev. Sci. Instrum. 51, 1342-1344, 1980.

Sondergeld, C.H. and L.H. Estey. Acoustic emission study during the cyclic loading of Westerly granite, J. Geophys. Res., in press, 1981. 


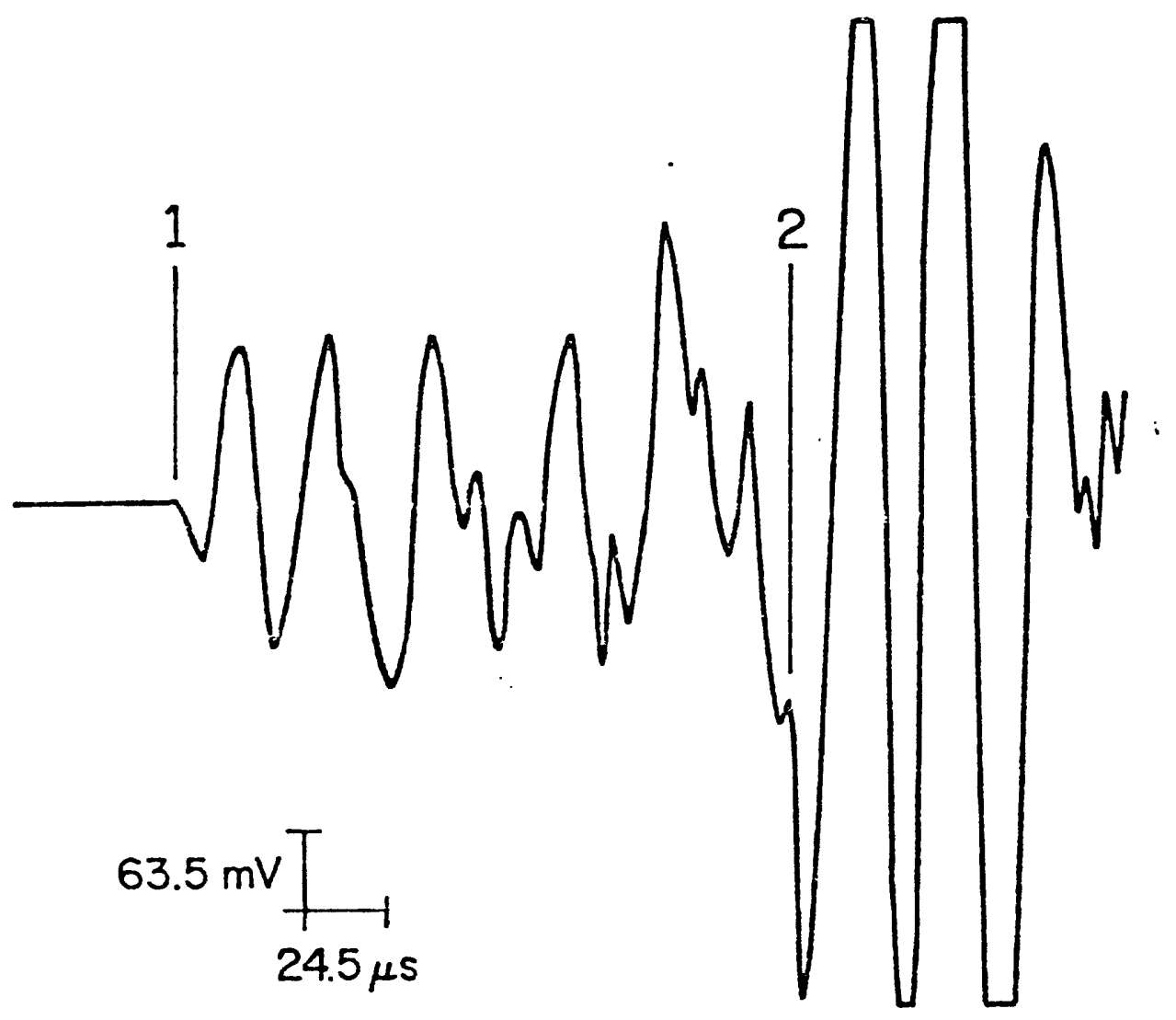

